\title{
Ironia e suspensão teleológica do geral em Søren Kierkegaard
}

\author{
Irony and teleological suspension of the general in Søren \\ Kierkegaard
}

\author{
Diogo Alves da Conceição Santana \\ Graduação em andamento em Filosofia (2013). Universidade do Estado do Rio de Janeiro - UERJ. \\ Instituto de Filosofia e Ciências Humanas, Rio de Janeiro, RJ - Brasil.
}

\begin{abstract}
Resumo: Segundo Søren Kierkegaard, a moralidade que se identifica com o geral, por sua vez, corresponde ao divino, posição assumidamente hegeliana. O dever torna-se então o limite axiomático pelo qual o indivíduo se relaciona com Deus. No entanto, relacionar-se com a norma estabelece uma diferença qualitativa, tornando a relação uma falsificação, já que não há equivalência entre Deus e a norma geral. Por outro lado, o indivíduo em relação ao geral também se perde como indivíduo. A alteridade em relação ao geral torna-se então a condição tanto de um relacionamento efetivo com Deus quanto de uma relação do indivíduo consigo mesmo. Essa alteridade é entendida por Kierkegaard como uma suspensão teleológica e, posteriormente, uma ressignificação das categorias como moralidade, dever e divindade. O político, a partir de uma perspectiva hegeliana, atravessa essa relação com o geral e, por isso mesmo, é cobiçado pelo projeto de suspensão teleológica de Søren Kierkegaard. Suspensão teleológica que para o filósofo dinamarquês é reconhecida como ironia. Para tanto, ao determinar seu conceito de ironia evoca a personalidade de Sócrates. Uma designação pontual da relação irônica entre tal personalidade com o estado e o político é inevitável. A personalidade de Sócrates evoca ironicamente uma oposição não só entre objetividade e subjetividade, exterior e interior, mas também entre o social como uma relação espontânea e ocasional entre indivíduos e o político como instrumento de coesão para a formação da multidão. Partindo da relação entre Sócrates e o Estado grego, apontado por Kierkegaard como irônico, e reconhecendo nesta relação uma suspensão teleológica, o presente trabalho busca estabelecer os critérios indicados por Kierkegaard para tal determinação.
\end{abstract}

Palavras-chave: Kierkegaard; ironia; suspensão teleológica; ironia; Hegel.

\begin{abstract}
According to Søren Kierkegaard the morality identifying itself with the general, in turn, corresponds to the divine, admittedly Hegelian position. Duty then becomes the axiomatic limit whereby the individual relates to God. However, to relate to the norm establishes a qualitative difference, making the relation a falsification, since there is no equivalence between God and the general norm. On the other hand, the individual in relating to the general also loses himself as an individual. The alterity in relation to the general then becomes the condition both for an effective relationship with God, and for a relation of the individual to himself. This alterity is understood by Kierkegaard as a teleological suspension and subsequently a re-signification of the categories as morality, duty and divine. The politician, from a Hegelian perspective, crosses this relationship with
\end{abstract}


the general, and for this very reason, is coveted by the project of teleological suspension of Søren Kierkegaard. Teleological suspension which for the Danish philosopher is recognized as irony. To do so, in determining his concept of irony evokes the personality of Socrates. A punctual designation of the ironic relationship between such personality with the state and the political is inevitable. The personality of Socrates thus ironically evokes an opposition not only between objectivity and subjectivity, exterior and interior, but also between the social as a spontaneous and occasional relationship between individuals and the politician as an instrument of cohesion for the formation of the multitude. Starting from the relation between Socrates and the Greek State, pointed out by Kierkegaard as ironic, and recognizing in this relation a teleological suspension, the present work seeks to establish the criteria indicated by Kierkegaard for such determination.

Keywords: Kierkegaard; irony; teleological suspension; morality; Hegel.

\section{Considerações Iniciais}

Segundo Álvaro Valls (1991, p. 10), O conceito de ironia, dissertação de 1841, constitui o plano geral, ainda em progresso de amadurecimento, dos principais elementos temáticos e metodológicos de toda a obra do filósofo dinamarquês Søren Kierkegaard. É, portanto, tomado como o "método" ou a plataforma que nos permite conjecturar intensões e estabelecer o desenvolvimento de algumas interpretações, tais como as polêmicas desenvolvidas pelo filósofo ao longo de toda a sua obra. Sendo assim, é natural encontrarmos nela posicionamentos que reverberam tanto em sua obra heteronímica quanto veronímica.

Dentre elas Temor e Tremor, obra publicada em 1843, heteronímica, atribuída a Johannes de Silentio. Destaca-se em tal obra uma original e provocante análise da narrativa bíblica do sacrifício de Isaque por Abraão (Gênesis, 22) e suas implicações morais ${ }^{1}$. No contexto, relações entre fé e moral, cultura e loucura, razão e ironia são avaliadas, a partir do pseudônimo de alguém que julga compreender bem a fé de Abraão, contudo, é incapaz de aderir a ela, segundo o que exige. É essa exigência que nos interessa como objeto para a presente pesquisa, que, em princípio, aproxima Abraão de Sócrates, e posteriormente os separa. Por essa razão, torna-se oportuna a relação entre as duas obras citadas e como suas problemáticas principais se relacionam.

\section{O Conceito de Ironia}

O conceito de ironia (1841) possui como orientação geral a determinação conceitual da ironia socrática por intermédio prévio da instituição de sua personalidade histórica. O problema consiste na disparidade dos relatos disponíveis ${ }^{2}$, que tornam problemática uma determinação universal e objetiva. Kierkegaard, por sua vez, compreende tal dificuldade como o caminho determinante para "uma concepção (opfattelse) confiável e autêntica da existência (Existents) historicamente real, fenomenológica de Sócrates" (KIERKEGAARD, 1991, p. 23). Posição tomada a partir de um diálogo com a dialética hegeliana.

O pressuposto para tal determinação possui forte inspiração na dialética hegeliana, contudo, com diferenças bem específicas. Segundo Hegel, o conceito é a mediação, com o que concorda Kierkegaard, no entanto, se para o primeiro a mediação tem em vista ideias, para o segundo, constitui uma exigência que a mediação leve em consideração o fenômeno. Enquanto Hegel descarta o histórico na participação da

\footnotetext{
${ }^{1}$ No contexto, partindo de um pressuposto hegeliano, não há uma distinção entre moral e ética, mas sim entre moral subjetiva e moral objetiva.

${ }^{2}$ Kierkegaard analisa os relatos disponíveis de Xenofonte e Platão (ambos discípulos de Sócrates que compõem apologias depois de sua morte) e de Aristófanes (comediante grego, autor de uma peça ridicularizando o filósofo grego).
} 
Ideia, Kierkegaard, por sua vez, descarta a Ideia na participação do histórico. Para o primeiro se destacam o universal e o absoluto, para o segundo o histórico e o particular. Pois, para Hegel, "o que se desenvolve sobre bases históricas não pode se confundir com o desenvolvimento a partir do conceito, nem a legitimação e explicação históricas atingem jamais o alcance de uma justificação em si e para si" (HEGEL, 1997, p. 5). Enquanto que para Kierkegaard "se bem que o observador traga o conceito consigo, importa, mesmo assim, que o fenômeno não seja violentado e se veja o conceito surgindo a partir do fenômeno" (KIERKEGAARD, 1991, p. 23).

Para Kierkegaard, a disparidade dos relatos disponíveis indica muito mais um ponto de vista do que uma determinação objetiva, enquanto que para Hegel tal disparidade equivaleria a elementos descartáveis na determinação da Ideia. Enquanto ponto de vista, isso expressa uma composição, de modo a acrescentar na personalidade socrática a determinação positiva que escapava a todos. Por esse princípio Xenofonte endossa a empiria e Platão a Ideia. Aristófanes, por intermédio da comédia, expressa a ambiguidade, que para Kierkegaard mais se aproximou do conteúdo negativo que a própria ironia de Sócrates representava.

Ironia, portanto, que não deve ser tomada como um simples instrumento retórico de convencimento, mas o inverso disso, como posição existencial cuja ambiguidade expressa confusão, mal-entendido, que, segundo Kierkegaard, não se supera. Condição que define a ironia como negativo, o irônico como "subjetividade egoisticamente encerrada em si mesma" (KIERKEGAARD, 1991, p. 123) e, por isso mesma, que torna a personalidade histórica de Sócrates incompreensível por seus contemporâneos e, depois deles, para os seus intérpretes românticos.

Temor e Tremor ${ }^{3}$, por sua vez, possui uma estrutura bem próxima à de Conceito de Ironia. Estabelece como orientação geral a determinação da fé de Abraão, isto é, de sua subjetividade, por intermédio prévio da eliminação das possibilidades positivas, universais e objetivas, que fariam "de um crime um ato santo e agradável a Deus, paradoxo que devolve a Abraão o seu filho, paradoxo que não pode reduzir-se a nenhum raciocínio, porque a fé começa precisamente onde acaba a razão" (KIERKEGAARD, 1974, p. 282). A relação entre uma obra e outra também não é ocasional. Se, por um lado, identifica Sócrates com Abraão na posição de que nenhum conteúdo positivo pode enfim superar o paradoxo que define tanto a tarefa socrática de indagar seus contemporâneos quanto a tarefa de Abraão de imolar o filho que tanto ama, por outro lado, separa-os radicalmente na intenção de determinar uma diferença qualitativa entre socratismo e a fé de Abraão, de maneira que a ironia as aproxima, mas a fé as separa.

\section{Suspensão Teleológica do Geral}

Sócrates e Abraão se identificam quando a possibilidade da tarefa implica o paradoxo. Distinguem-se, porém, qualitativamente no que o paradoxo exige ${ }^{4}$. Paradoxo que implica uma suspensão teleológica do geral. O geral constitui a grande obsessão da filosofia do direito de Hegel. Hegel entende que a filosofia trata especificamente da Ideia. O conceito, portanto, constitui a mediação necessária à realização das formas abstratas. A Ideia corresponde à manifestação do conceito (HEGEL, 1997, p. 1) na objetividade, pois "na objetividade reside a verdade da certeza" (HEGEL, 1997, p. 148). A objetividade constitui a identidade entre o universal e o particular. É nesse sentido

\footnotetext{
${ }^{3}$ Segundo Gouvêa (2000), deve-se levar em consideração que Temor e Tremor, é escrito pelo pseudônimo Johannes de Silentio, que não é um cristão, porém, alguém que entendendo a profundidade da vida na fé sente-se incapaz de ir adiante. É o estágio denominado ético religioso ou religiosidade A.

${ }^{4}$ Pois a partir dai há categorias que o grego não contempla, como pecado e graça. O paradoxo, para o grego, limita-se então ao terreno moral, ao dever para consigo. Para o cristão, porém, impõe o dever para com Deus.
} 
que Hegel distingue uma moral objetiva de uma moral subjetiva, correspondendo esta última ao que não é idêntico pois "Com efeito, o desejo de ser algo de particular não se adequa ao universal em si e para si. Só na exceção se encontra a consciência da singularidade" (HEGEL, 1997, p. 145). Posição que deve ser suprimida na teleologia da moralidade, segundo o filósofo alemão, porquanto "o caráter moral objetivo conhece que seu fim motor é o universal, imutável se bem que aberto em suas determinações à racionalidade real, e reconhece que a sua dignidade, assim como tudo o que na existência assegura os seus fins particulares, se funda neste universal onde realmente os encontra" (HEGEL, 1997, p. 147).

Para Hegel, a substância universal da moral objetiva é consagrada na vida pública (HEGEL, 1997, p. 149), que segundo ele constitui "o Espírito real de uma família ou de um povo" (HEGEL, 1997, p. 148). As etapas ou o movimento executado pelo conceito em direção a essas ideias atravessam o espírito moral objetivo imediato através da família, sociedade civil e, por fim, do Estado. O Estado é, portanto, "a realidade em ato da Ideia moral objetiva" (HEGEL, 1997, p. 216).

É se referindo à moral objetiva hegeliana que Johannes de Silentio compreende a moral como situada no geral, aplicável a todos, a todo instante ${ }^{5}$. Participando "da mesma natureza da eterna felicidade do homem" (KIERKEGAARD, 1974, p. 283), a moralidade compreende assim uma identidade teleológica com o divino (KIERKEGAARD, 1974, p. 292). Negar essa posição da moralidade corresponde a afirmar que essa mesma pode ser ideologicamente suspensa ${ }^{6}$. Negação estabelecida por uma crise que exige a reintegração do indivíduo no geral, o que significa perder-se como indivíduo, ou a suspensão do geral tendo em vista seu telos no divino. Posições que não se equivalem, pois "estar suspenso não significa perder-se, mas conservar-se na esfera superior que é o seu telos" (KIERKEGAARD, 1974, p. 283), o que na perspectiva hegeliana, segundo Kierkegaard, equivaleria a uma "forma ética do mal, ou seja, expressão do particular no geral" (KIERKEGAARD, 1974, p. 283).

O Indivíduo quem, depois de ter estado como tal subordinado ao geral, alcança ser agora, graças ao geral, o Indivíduo, e como tal superior a este; de maneira que o Indivíduo como tal encontra-se numa relação absoluta com o absoluto. Esta posição escapa à mediação que se efetua sempre em virtude do geral. Ela é e permanece eternamente um paradoxo inacessível ao pensamento. (KIERKEGAARD, 1974, p. 284)

A suspensão teleológica do geral corresponde a uma "reivindicação da individualidade, depois deste mesmo indivíduo ter entrado no geral" (KIERKEGAARD, 1974, p. 283), isto é, significa participar de todas as etapas pelas quais a moral objetiva se torna realidade em ato, significa tornar-se indivíduo a partir do movimento de perder-se como tal no geral. Ora, não participa a ironia socrática do mesmo processo quando o filósofo grego toma para si o isolamento pessoal? Não corresponderia ao crime contra o Estado justamente a condução de outros tantos à mesma expressão particular no geral? Não seria isso mesmo o mal numa perspectiva hegeliana? Bastariam os gregos então para explicar Abraão como um recorrente caso de ironia? Sócrates poderia, ao lançar um indivíduo para fora da realidade do Estado, torná-lo um irônico como ele (embora permanecesse um mistério), por outro lado, ninguém pode imitar Abraão, o que o torna impossível de ser pensado, repetido.

Se, por um lado, a fé exige aquela mesma suspensão teleológica do geral tão próxima à ironia socrática, por outro lado, evoca de igual maneira uma distância radical. Pois os gregos não conhecem as categorias de pecado e fé, sendo por isso mesmo o geral reconhecido como divino e a reivindicação de individualidade de

\footnotetext{
${ }^{5}$ Entretanto, cabe ressaltar, Johannes não é um hegeliano, mas alguém que entendeu Hegel, e vê no cristianismo sua superação imediata, contudo, não tem a coragem necessária para realizar o movimento de um ao outro.

${ }^{6}$ Há uma evidente distinção entre fé e moral no postulado. Postura oriunda da fé luterana em suas origens.
} 
Sócrates ser legítima como um mal em seu contexto. O que torna Hegel um bom interprete dos gregos nesse sentido, mas não da fé de Abraão e do cristianismo.

A moralidade, em si, está no geral, e a este título é aplicável a todos. O que pode por outro lado, exprimir-se dizendo que é aplicável a cada instante. Repousa imanente em si mesma, sem nada exterior que seja o seu telos sendo ela mesma telos de tudo o que lhe é exterior; e uma vez que se tenha integrado nesse exterior não vai mais além. Tomado como ser imediato, sensível e psíquico, o Indivíduo é o Indivíduo que tem o seu telos no geral; a sua tarefa moral consiste em exprimir-se constantemente, em despojar-se do seu caráter individual para alcançar a generalidade. (KIERKEGAARD, 1974, p. 283)

A ironia socrática corresponde a um ponto de vista negativo frente a qualquer positividade, o que inclui o Estado e o exercício objetivo do poder, no qual sua personalidade recusava integrar-se. Como consequência, sua visão subjetiva, ironicamente, situava-se contra a soberania do povo e o julgamento objetivo do Estado, de maneira que sua condenação à morte não representava nenhuma realidade, pois "Sócrates não sabe simplesmente nada, eneste sentido é uma ironia sobre o Estado, que o condena a perder a vida, e com isso crê que o puniu" (KIERKEGAARD, 1991, p. 235). Sua missão divina de indagar seus contemporâneos privava-o de tempo e oportunidade para dedicar-se ao Estado, à família e a outros assuntos de caráter público (KIERKEGAARD, 1991, p. 141). Deslocava-se, assim, da posição de cidadão e sua ação não poderia por isso receber no âmbito público uma qualificação ou predicado de qualquer espécie. Era um homem sem títulos (KIERKEGAARD, 1991, p. 142). O embate com o Estado ocorre não pela decisão de Sócrates de viver como um homem privado, mas sim por induzir outros tantos a lançarem-se para fora da realidade pública como ele, configurando o crime de tornar o Estado ausente daquela mesma substancialidade que somente pode ser conferida a ele por intermédio da adesão à tradição.

Por outro lado, Kierkegaard reconhece que muito embora a ironia não tenha como orientação a suspensão da realidade como um todo, mas sim da realidade dada a uma certa época, pois:

Se se levar em conta que mesmo em nossos países, quando o Estado, justamente porque atravessou uma mediação muito mais profunda, já reconhece à subjetividade um espaço completamente diferente, muito mais do que o Estado grego era capaz de fazer, se mesmo aí, digo eu, em nossos Estados, um "particular" continua a ser uma pessoa ambígua, então se poderá daí deduzir com que olhos o Estado grego deve ter considerado a tentativa de Sócrates de andar o seu caminho por conta própria e levar a vida como um homem privado. (KIERKEGAARD, 1991, p. 141)

É nesse sentido que o empenho socrático não se encontra limitado a uma específica realidade dada no passado, mas nos alcança enquanto tarefa a ser executada diante do paradoxo determinado em nosso próprio tempo. Sócrates não é um homem de partido. Sua ironia impulsiona a cisão que garante a liberdade necessária à indiferença ao pathos cívico e aos interesses do Estado; por outro lado, ele dedica-se apaixonadamente à sua missão de conversação, isolamento pessoal e ao trato com todos os homens, que para ele representavam, situados nas mais diversas representações sociais, apenas uma soma de indivíduos. Seu interesse pelo indivíduo o situava acima dos interesses partidários que garantem a manutenção do poder. Por outro lado, não há qualquer conteúdo conquistado por essa relação, pelo contrário, nela todo conteúdo é privado, determinando assim todo o processo de conquista de si mesmo.

E quanto mais ele se mostrava inflexível em não se submeter ao Estado, tanto mais flexível, tanto mais maleável ele era no trato com os homens, tanto maior virtuose dos encontros casuais. Ele gostava igualmente de falar com agricultores, alfaiates, sofistas, homens do Estado, poetas, com jovens e velhos, falava facilmente sobre todos os assuntos, porque em toda parte encontrava uma tarefa para sua ironia. Mas em tudo isso não era certamente um bom cidadão e certamente não tornava melhores cidadãos os outros. Se o ponto de vista de Sócrates era realmente superior ao do Estado, se ele em verdade estava autorizado pela 
divindade, sobre isto a história universal deve julgar, mas se ela deve julgar razoavelmente, então tem de conceder ao mesmo tempo que o Estado estava autorizado a condenar Sócrates. Num certo sentido, ele era, portanto, revolucionário, contudo não tanto ao fazer alguma coisa quanto ao se omitir de fazer algo; mas homem de partido ou cabeça de um complô ele não era, disto o preservava a ironia; pois assim como esta o privava da verdadeira simpatia do cidadão pelo Estado, do verdadeiro "pathos" cívico, também o livrava daquela morbidez e daquela exaltação que é condição para um homem de partido. Sua posição era por demais a de uma isolação pessoal. (KIERKEGAARD, 1991, pp. 142-143)

\section{Ironia, Razão e Paixão Religiosa}

Sendo o geral aplicável a todos a todo instante (KIERKEGAARD, 1974, p. 283), é exigido dele um constante movimento de repetição, o que significa a exigência permanente do particular, tendo, como tarefa moral, despojar-se constantemente de seu caráter individual em vista da generalidade. Movimento que paradoxalmente constitui a possibilidade de suspensão dessa generalidade, quando o Indivíduo "reivindica a sua individualidade frente ao geral" (KIERKEGAARD, 1974, p. 283). Por sua vez, reivindicar essa individualidade constitui de igual maneira uma repetição, que para tanto exige um movimento em direção ao geral. A moralidade, assim como a fé, corresponde ao permanente movimento de integração no geral e isolamento pessoal. Movimento que indica uma suspensão, seja do indivíduo (constituindo a moralidade), seja da moralidade (constituindo a fé). A correspondência se estabelece pelo movimento, por outro lado, se distingue pelo telos. A moralidade, enquanto telos da individualidade, exige o constante despojamento desta última, assim como a individualidade, assumida como telos, exige o constante despojamento da generalidade, posto que:

a fé é esse paradoxo segundo o qual o Indivíduo está acima do geral, mas de tal maneira que, e isso importa, o movimento se repita e, por consequência, o Indivíduo, depois de ter permanecido no geral, se isole logo a seguir, como Indivíduo acima do geral. (KIERKEGAARD, 1974, p. 283)

O constante movimento de repetição exige uma suspensão que se identifica com o irônico. Constitui uma suspensão, posto que "estar suspenso não significa perder-se, mas conservar-se na esfera superior que é o seu telos" (KIERKEGAARD, 1971, p. 283). Suspensão que é ironia e que se distingue quantitativa e qualitativamente pela natureza do movimento exercido: a suspensão do individual tendo em vista o geral compreende a ironia em seu sentido retórico, comum, que se dedica à suspensão de casos particulares. Por outro lado, a suspensão do geral tendo em vista o individual compreende a ironia em seu sentido filosófico, existencial, identificada de maneira paradigmática na figura socrática.

A diferença entre todas essas manifestações de ironia até aqui mencionadas é, portanto, apenas quantitativa, um mais ou menos, enquanto a ironia sensu eminentiori (no sentido mais elevado, mais próprio) se diferencia qualitativamente da ironia até aqui descrita, assim como a dúvida especulativa se diferencia qualitativamente da dúvida vulgar e empírica. A ironia sensu eminentiori não se dirige contra este ou aquele existente individual, ela se dirige contra toda a realidade dada em uma certa época e sob certas condições. (KIERKEGAARD, 1991, p. 221)

No âmbito alegórico, o movimento de suspensão do geral em direção ao particular é tipificado poeticamente por Johannes de Silentio através da figura do bailarino, que se ergue do chão por um salto, e, com perfeita habilidade, elegantemente pousa no chão - mesmo quando não consegue equilibrar-se completamente, retorna continuamente o movimento. 
Imagino que, para um bailarino, o esforço mais difícil consiste em colocar-se, de um só golpe, na posição precisa, sem um segundo de hesitação. É possível que não exista um acrobata com tal habilidade e domínio: tem-na, porém, o meu cavaleiro. Muitos homens dominados pelos cuidados e prazeres do mundo: assemelham-se àqueles que vão à festa sem dançar. Os cavaleiros do infinito são bailarinos a quem não falta elevação. Saltam no ar e logo voltam a cair, o que não deixa de constituir passatempo divertido e nada desagradável à vista. Mas de cada vez que recaem não podem, logo no primeiro momento, guardar completo equilíbrio. Por instantes vacilam indecisos, o que logo mostra que são estranhos ao mundo (...). Voltar, porém, a cair de tal modo que se dê a impressão do êxtase e da marcha ao mesmo tempo; transformar em andamento o passo normal do salto; exprimir o impulso sublime num passo terreno; eis o único prodígio de que só é capaz o cavaleiro da fé. (KIERKEGAARD, 1974, p. 274)

O cavaleiro da fé, ao realizar o movimento de suspensão teleológica da moral, identifica-se com o irônico, "é expressão do supremo egoísmo: realiza o terrificante, realiza-o por amor de si próprio" (KIERKEGAARD, 1974, p. 294), entretanto, paradoxalmente, distingue-se dele por executar seu movimento a partir da categoria do pecado e do dever para com Deus "por outro lado é a expressão do mais absoluto abandono, atua por amor de Deus" (KIERKEGAARD, 1974, p. 294). A ironia enquanto categoria existencial qualifica-se então a partir de um patamar filosófico com Sócrates e, outro, religioso, com Abraão. Distinguem-se, dessa maneira, pois enquanto Sócrates exige sua individualidade diante do geral, Abraão, por sua vez, não apenas a exige diante do geral, mas também de uma instância superior a ele e por isso o religioso é indicado por Johannes de Silentio como uma instância acima, pois atravessa aquela mesma dimensão da existência onde se torna impossível falar. Existência singular.

Gouvêa muito bem esclarece, que a intensão de Kierkegaard através de seu pseudônimo Johannes de Silentio consiste em:

\begin{abstract}
falar sobre a relação entre fé e razão, e de apresentar Abraão como o "cavaleiro da fé", modelo maior de vida de fé em virtude do "absurdo" (do paradoxo), e explicar, em oposição ao hegelianismo, por que a fé não é inferior à razão, mas sim um dom superior e espetacular, um longo e duro aprendizado, uma paixão feliz, uma divina loucura, e um complexo "movimento duplo" do espírito humano. (GOUVÊA, 2000, p. 234)
\end{abstract}

\title{
Conclusão
}

A moral, compreendendo o movimento do indivíduo ao geral, pressupõe a exceção quando o indivíduo, depois de integrar-se a generalidade, reivindicando sua individualidade, realiza o movimento inverso. A generalidade é, por sua vez, teleologicamente suspensa. Posição que pode ser determinada como ironia ou fé, que se distinguem qualitativamente pelas categorias presentes nesta última, as do pecado e da graça, mas que se identificam enquanto negativo que a tudo esvazia de conteúdo, paradoxo. A fé exige ironia, aquela mesma disposição de espírito à singularização, que os gregos concebiam como um mal, desagregando os homens da vida pública e motivando-os ao permanente cultivo da vida interior. A ironia, por outro lado, enquanto condição prévia, nada pode exigir da fé. Abraão vai mais longe que Sócrates.

Segundo Kierkegaard, Sócrates recusa-se com sua ironia a ser um homem de partido. Postura inversamente proporcional ao seu interesse pelo indivíduo, independente de sua posição social e ideologia. Tornar-se, pois, indivíduo constitui, para ele, Kierkegaard, a tarefa por excelência que, muito embora relegue à indiferença os diversos instrumentos de coesão social, torna mais flexíveis as relações humanas, pois implica olhar o outro de igual maneira como indivíduo, individualmente. 
Correspondência: Diogo Alves da Conceição Santana. Universidade do Estado do Rio de Janeiro - UERJ. Instituto de Filosofia e Ciências Humanas. Rua São Francisco Xavier, 524. Maracanã. Rio de Janeiro - RJ - Brasil. CEP: 20550-01. E-mail: diogosantana45@yahoo.com.br.

Apoio financeiro: Nenhum.

Conflito de interesses: Nenhum.

Todos os autores leram e aprovam a versão final submetida à revista Em curso. 


\section{Referências Bibliográficas}

GOUVÊA, R. Q. Paixão pelo Paradoxo: uma introdução aos estudos de Soren Kierkegaard e de sua concepção

de fé cristã. São Paulo: Ed. Novo Século, 2000.

HEGEL, G. W. F. Princípios da Filosofia do Direito. São Paulo: Ed. Martins Fontes. 1997.

KIERKEGAARD, S. O Conceito de Ironia, constantemente referido a Sócrates. Ed. Vozes, 1991.

Temor e Tremor. Ed. Abril Cultural, 1974. (Coleção “Os Pensadores”)

VALLS, Á. Apresentação. In: KIERKEGAARD, S. O Conceito de Ironia, constantemente referido a Sócrates. Ed. Vozes, 1991.

Recebido em: 24/Mai/2018 - Aceito em: 26/Ago/2018. 